\title{
Review Article \\ Role of Macrophages in the Pathogenesis of Atopic Dermatitis
}

\author{
Sadaf Kasraie ${ }^{1}$ and Thomas Werfel ${ }^{2}$ \\ ${ }^{1}$ Global Preclinical Drug Discovery, Department of Molecular Pharmacology, Grünenthal GmbH, Zieglerstrße 6, \\ 52078 Aachen, Germany \\ ${ }^{2}$ Division of Immunodermatology and Allergy Research, Department of Dermatology and Allergy, Hannover Medical School, \\ 30625 Hannover, Germany
}

Correspondence should be addressed to Sadaf Kasraie; sadafkasraie@gmail.com

Received 15 October 2012; Revised 17 January 2013; Accepted 18 January 2013

Academic Editor: Chiou-Feng Lin

Copyright (C) 2013 S. Kasraie and T. Werfel. This is an open access article distributed under the Creative Commons Attribution License, which permits unrestricted use, distribution, and reproduction in any medium, provided the original work is properly cited.

\begin{abstract}
Atopic dermatitis (AD) is one of the most common and most intensively studied chronic inflammatory skin diseases. Several cofactors, such as an impaired skin barrier function, modifications of the immune system, and a complex genetic background, direct the course of AD. Within this complex network, macrophages play a pivotal role in enhanced susceptibility to cutaneous infections and act as central connecting components in the pathogenesis of $\mathrm{AD}$ on the cellular level. In $\mathrm{AD}$, macrophages are known to accumulate in acutely and chronically inflamed skin. During the early and short inflammatory phase, macrophages exert proinflammatory functions like antigen-presenting phagocytosis and the production of inflammatory cytokines and growth factors that facilitate the resolution of inflammation. However, persistence of pro-inflammatory activity and altered function of macrophages result in the development of chronic inflammatory diseases such as AD. The exact mechanism of macrophages activation in these processes is not yet completely understood. Further studies should be performed to clarify the dysregulated mechanism of macrophages activation in $\mathrm{AD}$, and this would allow us to target these cells with versatile functions for therapeutic purpose and improve and control the disease. In this paper, we highlight the new findings on dysregulated function of macrophages and the importance of these cells in the pathogenesis of $\mathrm{AD}$ in general and the contribution of these cells in enhanced susceptibility against microbial infections in particular.
\end{abstract}

\section{Introduction}

Besides providing a structural barrier, the skin contains several immune cells that can be activated by invading pathogens or skin damage. One of the most important immune cells involved in inflammation and wound healing is the macrophage, which exhibits different immunological functions in the skin, including phagocytosis and antigen presentation. Furthermore, macrophages produce many cytokines and chemokines that stimulate new capillary growth, collagen synthesis, and fibrosis [1]. This immune cell is thought to orchestrate the resolution of inflammation and the wound healing process throughout the different phases such as haemostasis, inflammation, proliferation, angiogenesis, and reepithelialisation as well as remodeling [13].

Researchers have long known that macrophages residing in or migrating to different tissues or sites of infection and damage have distinct appearances and cell surface phenotypes; for example, Kupffer cells (liver resident macrophages) appear microscopically different than splenic red pulp macrophages. Until recently, phenotyping macrophages and other related mononuclear phagocytes, including the many dendritic cells (DCs) subtypes, with cell surface markers such as CD11b, CD68, macrophage antigen-2, and F4/80, has been the mainstay of macrophage characterization. However, the last decade has provided new ways of phenotyping macrophages based on their gene-expression profile in response to specific stimuli. By far, the most often-used terms in gene-expression-based macrophage phenotyping are classically activated macrophages (CAMs) (also called M1) and alternatively activated macrophages (AAMs) (M2), which are thought to have characteristic gene-expression profiles defined by markers linked to the stimulation conditions used to generate the subtype-toll-like receptor (TLR) stimulation, bacterial infection, and interferon-(IFN-) $\gamma$ stimulation for 
CAMs and IL-4/IL-13 for AAMs. It is not surprising that given tendencies of immunologists for cell categorization, CAMs and AAMs have been atomized into smaller tranches such as M1a and M2a and M2b. A major question, therefore, concerns the function of the different macrophage types in different homeostatic, infection, and tissue-repair scenarios. Surprisingly, little is known about the functions of individual AAM-associated genes in comparison with CAMassociated macrophage-inflammatory and tissue-remodeling products. However, the gap in knowledge concerning AAM effector functions is closing rapidly with recent publications investigating the effects of deletion of two AAM-associated effector genes, Arg1 and Retnla. Furthermore, correlations between mouse and human tissue macrophages and their representative subtypes are lacking and are a major barrier to understanding human immunity [4].

Macrophages play key roles in inflammation [5]. During the onset of the inflammatory process, these phagocytic cells become activated and have destructive effects. Macrophage activation, which involves the induction of more than 400 genes, results in an increased capacity to eliminate bacteria and to regulate many other cells through the release of cytokines and chemokines. However, excessive activation has damaging effects, such as septic shock, which can lead to multiple organ dysfunction syndrome and death. In other situations, persistence of proinflammatory activity results in the development of chronic inflammation including chronic inflammatory skin diseases such as psoriasis and atopic dermatitis (AD) [5].

$\mathrm{AD}$ is one of the most frequent chronic inflammatory skin diseases with an increasing prevalence affecting $10 \%-20 \%$ of children and $1 \%-3 \%$ of adults in industrial countries $[6,7]$. It has a significant impact on the quality of life of patients and their families, and the economic impact is estimated to be billions of dollars [8].

Patients with $\mathrm{AD}$ have frequent bacterial and viral skin infections. The most predominant bacteria on $\mathrm{AD}$ skin are Staphylococcus aureus, constituting 90\% of the bacterial microflora on lesional skin and importantly colonizing normal-appearing skin [9]. Many studies have shown that the extent of $S$. aureus colonization positively correlates with the disease activity of AD [10].

Several cofactors, such as an impaired skin barrier function, modifications of the immune system, and a complex genetic background, direct the course of $\mathrm{AD}$ [11-13].

Activation of T lymphocytes, DCs, macrophages, keratinocytes, mast cells, and eosinophils is characteristic of $\mathrm{AD}$ skin inflammatory responses.

Clinically unaffected skin in $\mathrm{AD}$ is not normal. It is frequently dry and has a greater irritant skin response than normal healthy skin. Microscopic studies reveal a sparse perivascular T-cell infiltrate in unaffected $\mathrm{AD}$ skin that is not seen in normal healthy skin. Acute AD skin lesions present to the physician as intensely pruritic, erythematous papules associated with excoriation and serous exudation. There is a marked infiltration of $\mathrm{CD}^{+}$activated memory $\mathrm{T}$ cells in acute AD. Antigen-presenting cells (e.g., Langerhans cells (LCs), inflammatory dendritic epidermal cells (IDECs), and macrophages) in lesional and, to a lesser extent, in nonlesional skin bear IgE molecules. Mast cell degranulation can be observed.

Chronic AD skin lesions have undergone tissue remodeling caused by chronic inflammation. These skin lesions are associated with thickened plaques with increased skin markings (lichenification), increased collagen deposition in the dermis, and dry fibrotic papules.

Macrophages dominate the dermal mononuclear cell infiltrate. Eosinophils also contribute to the inflammatory response, and $\mathrm{T}$ cells remain present, although in smaller numbers than seen in acute AD [14].

Within this complex network, antigen-presenting cells such as dendritic cells (DCs) and macrophages play a pivotal role as central connecting components on the cellular level.

Monocytes are important previous cells of macrophages that are involved in skin inflammation of AD [15]. Monocytes invade the dermis and differentiate into macrophages, which can also act as antigen-presenting cells (APCs) [16].

In $\mathrm{AD}$, macrophages are known to accumulate in acutely and chronically inflamed skin [17]. In this paper, we highlight the new findings on dysregulated function of macrophages and the importance of these cells in the pathogenesis of AD in general and the contribution of these cells in enhanced susceptibility against microbial infections in particular.

\section{Tissue-Specific Macrophage during Cutaneous Inflammation in AD}

Mononuclear phagocytes include tissue-resident cells, such as macrophages and DCs as well as blood monocytes and myeloid progenitors. These progenitors travel through the blood and lymphatic circulation to seed both lymphoid and nonlymphoid tissues, where they develop further, acquiring specific effector functions. DCs are uniquely specialised to detect perturbations originating from both outside and inside the organism. DCs possess the capacity to respond to infectious or noninfectious stress signals, and, following stimulation, they first initiate and then regulate adaptive immunity. DCs function is highly plastic; they can adapt their functional characteristics appropriately, when homing to tissue microenvironments as varied as the skin, the lung, or the gut mucosa. Similarly, when macrophages seed different tissues, they must also adapt and respond to the specific microenvironment. Macrophages and DCs are derived from myeloid bone marrow progenitors and reach the tissues via the blood, yet occupy distinct functional niches; so, it is highly pertinent to determine their precise lineage and progenitors. Once identified, it should be possible to answer long-standing questions concerning when and where in the body specific DC or macrophages commitment occurs and so better understand their differing immune properties in vivo and perhaps how they might be better manipulated therapeutically.

Analysis of the origins of mononuclear phagocytes and their pathways of differentiation have been hampered for decades by a lack of molecular markers with defined specificity for particular precursors or subpopulations. To date, much of our understanding of human DC is based on in vitro 

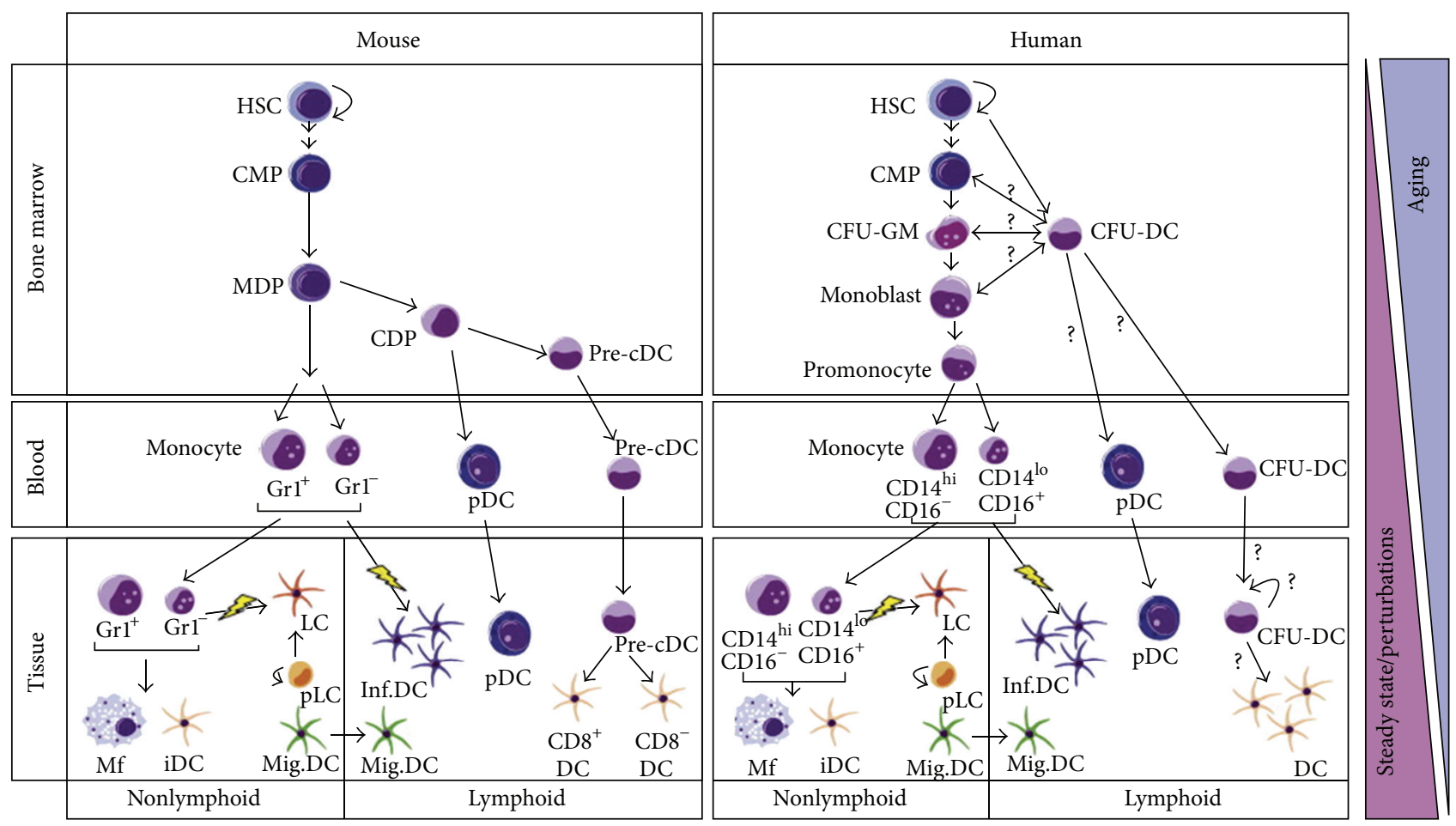

FIGURE 1: Mononuclear phagocyte differentiation in mouse and human. Hematopoiesis in mouse and human begins from the hematopoietic stem cells (HSCs). The HSCs are self-renewing with clonogenic and multipotent features, giving rise to all blood and tissue-resident immune cells. A very small number of HSCs generate immune cells de novo through a multistep differentiation process passing through multilineage progenitors first and to committed progenitors later. All of this process is strictly regulated according to physiological requirements, be it in the steady state or in response to external perturbations, such as infection. Aging also profoundly affects the function of the immune system. The phenomenon is attributable mainly to changes in the HSC compartment that probably gradually reduces its capacity for self-renewal, leading to a progressive reduction in the numbers of immune cells. Myeloid differentiation starts from a common myeloid progenitor (CMP) in the bone marrow. In the mouse, the destiny of CMP is better characterized compared to that of the human counterpart. The CMP generates macrophage-(Mf-) dendritic cell (DC) precursors (MDPs), which are considered the direct progenitor of Gr1 ${ }^{+}$and $\mathrm{Grl}^{-}$monocytes in the blood. Besides monocytes, the MDP differentiates into the common DC precursor (CDP), which in turn generates plasmacytoid DC (pDC) and progenitors for conventional DC (pre-cDC). pDC and myeloid DC diverge at the CDP stage. Pre-cDCs migrate out of the BM through the blood circulation into secondary lymphoid tissues (spleen and lymph nodes), where they replenish both $\mathrm{CD} 8^{+}$and $\mathrm{CD} 8^{-} \mathrm{DC}$ in the tissues. In humans, CMPs differentiate to granulocyte-macrophage (CFU-GM) precursor, which give rise to monocytes (CD14 ${ }^{\text {hi }} \mathrm{CD} 16^{-}$and $\mathrm{CD} 14^{\text {lo }} \mathrm{CD} 16^{+}$) through subsequent differentiation steps, monoblast first, followed by promonocyte. A DC precursor (CFU-DC) derived from $\mathrm{CD} 34^{+}$HSC with unique differentiation potential towards DC has been identified in bone marrow of the mouse, suggesting that a DC progenitor might exist in humans. Blood monocytes $\left(\mathrm{Grl}^{+}\right.$and $\mathrm{Grl}^{-}$in mouse, $\mathrm{CD} 14^{\text {hi }} \mathrm{CD} 16^{-}$and $\mathrm{CD} 14^{\text {lo }} \mathrm{CD} 16^{+}$in humans) migrate to nonlymphoid tissues and generate macrophages (Mfs) and interstitial DC (iDC). In the presence of environmental perturbation in vivo or of cytokines in vitro, $\mathrm{Grl}^{+}$or $\mathrm{Grl}^{-}$monocytes in mice and $\mathrm{CD}^{+} 6^{+}$or $\mathrm{CD}^{-} 6^{-}$monocytes in humans differentiate into Langerhans cells (LCs) in the epidermis, as well as inflammatory DC (Inf.DC). LCs are generated by a dermal long-term precursor (pLC) in the steady state. Finally, migratory DC (Mig.DC) moves between nonlymphoid and lymphoid compartments.

generated cells; however, it is still unknown to what extent they faithfully reproduce the phenotype and function of tissue DC. There is an urgent need to identify and characterise DC progenitors from human blood and to use these "untouched" cells to better understand specific DC functional capabilities. It is possible that certain blood monocyte subpopulations, such as $\mathrm{CD} 14^{+} \mathrm{CD} 16^{+}$monocytes, might retain some functional characteristics of DC; for example, they can exhibit enormous plasticity and heterogeneity and may have a role in a range of human diseases (Figure 1) [18].

Macrophages and DCs may play a role in chronicity of $\mathrm{AD}$ [11]. However, so far, only limited data are documented on the distribution of macrophages in the skin during cutaneous inflammation.
Kiekens et al. [17] characterized monocytes-derived cells in affected lesional $\mathrm{AD}$ skin, compared with nonaffected $\mathrm{AD}$ skin and healthy skin. They showed that there was an increase in macrophage numbers in acutely and chronically inflamed $\mathrm{AD}$ skin, whereas absolute $\mathrm{DC}$ numbers were unchanged, compared with nonlesional AD skin.

The macrophage markers RFD7 (mature tissue phagocyte marker) and CD68 show similar expression patterns during acute and chronic cutaneous inflammation. The total number of RFD7 $7^{+}$macrophages was lower than the number of $\mathrm{CD} 68^{+}$ macrophages [17].

Healthy human skin macrophages are known to express CD36, and functionally CD36 is linked to phagocytosis of apoptotic cells $[19,20]$. 
In acutely and chronically inflamed $\mathrm{AD}$ skin, Kiekens et al. [17] found increased expression of CD36 by macrophages. In inflamed tissue, many immune cells go into apoptosis after fulfilling their effector function and need to be removed efficiently. Increased expression of CD36 by macrophages may be linked to the removal of apoptotic cells [17].

Human monocyte-derived DCs express mannose receptors (MRs), as was shown by in vitro studies, and these cells use the MR for efficient antigen uptake [21]. In peripheral tissues such as the skin, antigen uptake is an important feature of resident macrophages and immature DCs. Both macrophages and DCs express MR in cutaneous inflammation; in nonlesional skin, their number is significantly increased compared with healthy skin. MRs are expressed mainly by macrophages in inflamed AD skin [17].

This can be explained by the fact that macrophages and not DC numbers increase in inflamed AD skin.

Furthermore, phenotypically heterogeneous and overlapping macrophage and DC populations are present in inflamed $\mathrm{AD}$ skin. The classic macrophage marker CD68 and prototypic DC marker CDla could bind to the same cell subpopulation in the dermis of inflamed AD skin [17]. Kiekens et al. [17] demonstrated that, within tissue-specific macrophage populations, further subpopulations are present and that monocyte-derived cells may express markers for both DCs and macrophages. Their results point to the existence of a heterogeneous pool of macrophage/dendritic celllike cells, from which subpopulations of dermal macrophages and DCs arise [17].

A recent study by Sugaya et al. [22] indicates that the numbers of $\mathrm{CD} 63^{+}$cells (alternatively activated macrophages marker) in lesional skin of $\mathrm{AD}$ were significantly larger than in normal skin. Interestingly, the number and distribution of $\mathrm{CD} 163^{+}$cells were quite similar to those of $\mathrm{CD}^{+} 8^{+}$cells which were consistent with a previous report [22].

Since in AD research most emphasis has been put on the regulatory role of $\mathrm{T}$ cells, little attention has been paid to the monocyte-derived macrophages and their potential role; no conclusive data are available on the distribution and clear phenotype of these cells in the skin of AD patients.

Therefore, further studies should be conducted in order to address the exact function of macrophages during different phases of the skin inflammation.

\section{Phagocytosis}

Individuals with $\mathrm{AD}$ frequently present recurrent infections from pyogenic bacteria or from intracellular microorganisms. The mononuclear and polymorphonuclear neutrophilic phagocytes participate in the innate defense, acting quickly against different agents. These cells initially present chemotactic activity, migrating towards the chemotactic factors and then to the area where the immune response takes place. Following this, phagocytosis occurs, which consists in the ingestion and digestion of the pathogenic organisms, with subsequent elimination of their inactivated products [23].

The high frequency of infections in individuals with $\mathrm{AD}$ suggests immune disorders, possibly involving the alterations of neutrophilic and mononuclear phagocytes. However, these alterations have not been fully understood in monocytederived macrophages $[23,24]$.

Forte et al. [25] observed a deficiency in the activity of mononuclear phagocytes in five patients with $\mathrm{AD}$ [25]. In another study, they evaluated phagocytes in 19 patients with $\mathrm{AD}$ and demonstrated that there was a reduction in the phagocytic activity by mononuclear phagocytes in patients with $\mathrm{AD}$ in all age groups studied. In the case of neutrophils, the same deficiency was observed only in patients with $\mathrm{AD}$ over 12 years of age [23].

Their data demonstrated a reduction in chemotactic response and phagocytic activity by neutrophilic and/or mononuclear phagocytes in the majority of patients with moderate to severe AD. Their results were coherent with the clinical data concerning the higher incidence of infections by pyogenic bacteria and fungi in patients with $\mathrm{AD}$, which are microorganisms that require defense by the phagocytes [23].

The recurrent infections by pyogenic bacteria or by intracellular organisms that occur in AD suggest that phagocytic activity disorders occur with greater frequency.

\section{Pattern Recognition Receptors (PRRs)}

The major players in the detection of invading pathogens are the recently identified TLRs. The success of TLRs to function as major sensors of invading pathogens is their ability to identify a range of conserved microbial motifs termed "pathogen-associated molecular patterns" (PAMPs). Innate recognition of PAMPs by TLRs can initiate a cascade of signaling pathways that eventually culminate in the induction of a wide range of immune and inflammatory genes. The most important products of these genes include chemokines and adhesion molecules which result in the recruitment of circulating monocytes from the bloodstream and the production of inflammatory cytokines such as tumour necrosis factor (TNF), interleukin-1 (IL-1), and IFN which mount an inflammatory immune response. As well as their initiation of the innate immune response, there is increasing evidence to suggest that TLRs can also play a role in other macrophage functions such as phagocytosis, antigen processing, and presentation and initiation of the adaptive immune response [26].

Evidence has shown that most of the ten TLRs are expressed on macrophages. In an early study where the mRNA expression of TLRs 1-5 was analysed in a fresh human leukocyte population containing monocytes, T lymphocytes, natural killer (NK) cells, DC, and polymorphonuclear (PMN) cells, TLR-1 was found to be ubiquitously expressed, whereas TLR-2, TLR-4, and TLR-5 were found on monocytes, DCs, and PMNs, and the expression of TLR3 appeared to be exclusively expressed on DCs $[27,28]$. Although macrophages were not analysed in this study, it is important to note that the expression of TLRs on monocytes can induce their activation so that they differentiate into either macrophages or DCs [29]. Further analysis has revealed that TLR-6, TLR7 , and TLR- 8 are also expressed on freshly isolated human monocytes, whereas TLR-9 and TLR-10 have been shown to be expressed on certain subsets of human DCs $[29,30]$. 
To add to the complexity, TLR expression appears to differ between mouse and human. For example, human TLR-3 appears to be exclusively expressed on DCs, whereas it is expressed and strongly induced in macrophages from mice. TLR-4 is expressed strongly on monocytes and macrophages in both species; however, TLR-4 mRNA expression increases upon LPS stimulation in human macrophages, whereas TLR$4 \mathrm{mRNA}$ is downregulated in response to LPS in murine macrophages [31]. In addition, TLR-9 appears to be almost exclusively expressed on plasmacytoid DCs in both humans and mice; however, in response to LPS, TLR-9 expression can be upregulated in murine macrophages $[29,32]$. Mice fail to express TLR-10; however, they express additional TLRs such as TLR-11, TLR-12, and TLR-13 which are absent in humans [33].

The mechanisms that promote the enhanced susceptibility to cutaneous infections in $\mathrm{AD}$ are complex interactions among several factors. These contributing factors include skin barrier dysfunction, reduced skin lipid content, and abnormalities of the innate immune response. Some of the innate immune defects observed in $\mathrm{AD}$ are primary defects such as epithelial barrier defects and defects in signaling or expression of innate receptors. Others may be secondary to the effects of the adaptive immune response. For example, deficiencies in antimicrobial peptides (AMPs) may be due to the overexpression of Th2 cytokines such as interleukin-(IL-) 4 and IL-13 [7, 34].

The innate immune system protects the host from pathogens and initiates the repair process following injury or trauma. It senses microbes through a group of germline encoded proteins, named pattern-recognition receptors (PRRs).

Host recognition of bacterial pathogens including $S$. aureus is mediated in part by PRRs, including membranebound toll-like receptors (TLRs) and intracellular nucleotidebinding oligomerization domain receptors (NLRs).

TLRs act as PRRs comprising a family of at least 10 receptors in humans with distinct recognition profiles [35]. In this context, TLR-2 has emerged as a principle receptor in combating Gram-positive bacteria, especially S. aureus [36, 37]. Of the key cells which express TLR-2 are monocytes and macrophages, and they contribute to eliminate pathogens.

TLR-2 forms heterodimers with TLR-1 and TLR-6 to interact with a rather broad spectrum of ligands. Studies using knockout mice identified TLR-1 as the coreceptor required for the recognition of triacylated lipoproteins and lipopeptides such as Pam3Cys [36]. Diacylated components such as lipoteichoic acid (LTA), which is a component of the cell wall of $S$. aureus, interact with TLR-2/TLR-6 heterodimers $[36,37]$. Peptidoglycan is a major constituent of the cell wall of Gram-positive bacteria, which induces signal transduction via TLR-2, nucleotide-binding oligomerization domain (NOD) 1 (card4), and NOD2 (card15) receptors, respectively.

NOD molecules, including NOD1 and NOD2, are a family of intracellular pattern recognition proteins involved in bacterial detection $[38,39]$. In this context, children with impetiginized AD were found to have increased levels of the TLR-2 ligand LTA in lesional skin that correlated with lesional
Eczema Area and Severity Index scores and S. aureus colonyforming units. Importantly, the amounts of LTA detected in lesional skin were sufficient to exert biological effects on various cell types in vitro [40].

There is emerging evidence that supports a general impairment of TLR-2 expression and TLR-2-mediated proinflammatory cytokines in monocytes and macrophages from $\mathrm{AD}$ patients $[41,42]$.

We could show that macrophages from patients with $\mathrm{AD}$ expressed significantly less TLR-2 compared with healthy controls, whereas the expression patterns of TLR-1 and TLR6 were not altered. Macrophages had a reduced capacity to produce proinflammatory cytokines such as IL-6, IL-8, and IL-1 $\beta$ after stimulation with TLR-2 ligands, which might contribute to the enhanced susceptibility to skin infections with $S$. aureus in $\mathrm{AD}$ [42]. Interestingly, weak TLR-2 and TLR-4 signals in the context of allergen exposure in the skin and lung, respectively, had previously been shown to promote a Th2-biased immune response [43]. Therefore, weak TLR2 responses may not only render $\mathrm{AD}$ patients incapable of eradicating $S$. aureus colonizing their skin, but may also promote a Th2 response.

Genetic TLR-2 polymorphisms have been shown to affect the severity of AD. A high frequency (12\%) of adult AD patients was found to carry the TLR-2 R753Q singlenucleotide polymorphism (SNP). These patients suffered from a more severe phenotype compared with $\mathrm{AD}$ patients without this mutation [44]. These data suggest that the TLR-2 polymorphism R753Q increases the susceptibility to infections and chronic colonization with various pathogens, including S. aureus.

In addition, we could show functional differences in TLR-2 responsiveness of monocytes from AD patients with the TLR-2 R753Q mutation compared with wild-type AD patients [45].

More recently, Nod2, an NLR protein which senses muramyl dipeptide produced during the synthesis and/or degradation of peptidoglycan, has been implicated in the host response to $S$. aureus [46]. While TLR2 and Nod2 induce immune responses via the activation of the transcription factor NF- $\kappa$ B and MAP kinases [47], another group of NLRs that include Nlrp3 and Nlrc4 are critical for the activation of caspase- 1 and IL- $1 \beta$ secretion in response to bacterial and endogenous stimuli in macrophages [48].

Previous studies have shown that IL- $1 \beta$ signaling and the adaptor protein Asc play a critical role in the clearance of $S$. aureus infection in the skin through monocytes and macrophages [49].

Muñoz-Planillo et al. [49] showed that $S$. aureus hemolysins including $\alpha$-toxin circumvent the requirement of ATP and the P2X7 receptor to induce caspase- 1 activation in macrophages via Nlrp3 inflammasome.

We recently showed that staphylococcal $\alpha$-toxin contributes to the Th1 polarization by induction of CXCL10 in macrophages. However, macrophages from patients AD show a reduced CXCL10 expression in response to staphylococcal $\alpha$-toxin [50]. Our data support the hypothesis that the contribution of macrophages in the pathogenesis of AD is linked to the presence of distinct alterations in their capacity to 
respond to the staphylococcal exotoxin $\alpha$-toxin and that these abnormalities can modulate the amplification and persistence of chronic skin inflammation [50].

The mechanism of macrophages activation by staphylococcal $\alpha$-toxin through inflammasome in monocytes and macrophages from patients with $\mathrm{AD}$ is not investigated yet.

Inflammasome-dependent mechanisms which may be altered in patients with resistant $\mathrm{AD}$ may contribute to the chronification of the disease and the susceptibility of patients with $\mathrm{AD}$ to cutaneous microbial colonization and infections.

Taken together, these data partially explain how macrophages contribute to skin colonization and infection with $S$. aureus and play a crucial role in chronic skin inflammation in $\mathrm{AD}$.

\section{The Cytokine and Chemokine Network}

Monocytes and macrophages are source of many cytokines and chemokines which play a fundamental role in pathogenesis of many chronic inflammatory diseases such as AD (see Table 1) [51-53].

Diversity and plasticity are hallmarks of cells of the monocyte-macrophage lineage. In response to IFNs, TLR engagement, or IL-4/IL-13 signaling, macrophages undergo M1 (classical) or M2 (alternative) activation, which represent extremes of a continuum in a universe of activation states. Progress has now been made in defining the signaling pathways, transcriptional networks, and epigenetic mechanisms underlying M1-M2 or M2-like polarized activation. Functional skewing of mononuclear phagocytes occurs in vivo under physiological conditions (e.g., ontogenesis and pregnancy) and in pathology (allergic and chronic inflammation, tissue repair, infection, and cancer) [54].

Macrophage subpopulations show different types of receptor expression and cytokine/chemokine production [55-59].

Classically activated macrophages, also called M1 cells, are induced by IFN- $\gamma$ and have a high capacity to present antigen. They produce inflammatory cytokines such as IL$1 \beta$, IL-6, IL-12, IL-23, and TNF- $\alpha$ as well as high levels of inducible nitric oxide synthase (iNOS).

In contrast, alternatively activated macrophages, also called M2 cells, are induced by IL-4, which promotes type 2 responses [55].

M2 macrophages are characterized by efficient phagocytic activity, high expression of several receptors such as class A scavenger receptor (CD204), MR, dectin-1, CD209, CD163, production of ornithine and polyamines through the arginase pathway, and an IL-12 ${ }^{\text {lo }}$ IL-10 ${ }^{\text {hi }}$ IL-1decoyR ${ }^{\text {hi }}$ IL-1RA ${ }^{\text {hi }}$ phenotype $[54,56,60]$.

Chemokine receptors and ligands are differentially modulated in polarized macrophages. In particular, production of IFN- $\gamma$-induced protein of $10 \mathrm{kDa}$ (IP-10/CXCL10) and monokine induced by gamma interferon (MIG/CXCL9) are inhibited by IL- 4 and IL-10. However, IL-4 selectively induces eotaxin-2/CCL24, CCL18, and macrophage-derived chemokine (MDC/CCL22) in macrophages, and these effects are inhibited by IFN $-\gamma$. Therefore, differential production of chemokines that attract Th1 (CXCL9, CXCL10) and Th2 or $\mathrm{T}$ regulatory ( $\mathrm{Tr}$ ) cells (CCL22) integrates $\mathrm{M} 1$ and $\mathrm{M} 2$ macrophages in circuits of amplification and regulation of polarized T-cell responses [60].

M1 cells are related with chronic inflammation and tumor inhibition, while M2 cells are related with tumor cell growth and metastasis through angiogenesis and tissue remodeling [22]. Allergy is driven by Th2 cells and products and is associated with M2 polarization of macrophages [61-63]. IL-4-inducible chemokines acting on CCR4 (e.g., CCL22) have also been reported to promote skewing of macrophage function [64]. Evidence now indicates that chitin- and arginase-dependent M2 pathways play an active role in the pathogenesis of allergy [65]. Asthma is associated with tissue remodeling, including collagen deposition and goblet cell hyperplasia. IL-4-driven M2 polarization is likely to play a key role as an orchestrator of these processes [66]. Allergy represents a paradigm for IL-4/IL-13-driven type 2 inflammation. However, there is evidence that the inflammasome/IL$1 /$ Th17 pathway can also drive allergic inflammation $[67,68]$. Moreover, a Th1-associated cytokine, IL-18, has also been implicated in allergic inflammation [69].

Patients with AD exhibit exaggerated Th2 responses, and initiation of $\mathrm{AD}$ lesions is thought to be mediated by means of early skin infiltration of Th2 lymphocytes releasing high levels of IL-4, IL-5, IL-13, and IL-31 [53, 70, 71]. Subsequently, the accumulation of activated monocytes, mature DCs, and eosinophils determines a rise in IL-12 expression and the appearance of a mixed Th2/Th1 cytokine pattern, with reduced IL- 4 and IL-13 and the presence of IFN- $\gamma$ in the chronic phase $[70,71]$. It is therefore perhaps not surprising that mixed phenotype macrophages (M2/M1) should be observed in AD which shows a mixed Th2/Th1 phenotype. However, there is no clear investigation in this area, and the exact mechanism of macrophages activation remains elusive. Further investigation should be performed to clarify the role of M2 and M1 in different phases of inflammation in AD.

In addition to the possible role of M2 and M1 macrophages in acute and chronic inflammation of $\mathrm{AD}$, there are several molecules and factors (e.g., histamine, staphylococcal components, cAMP, and FceRI ligation) which regulate cytokines and chemokines secretion through monocytes and macrophages in $\mathrm{AD}$ [72-75].

5.1. Histamine. For instance, histamine influences the profile of proinflammatory and immunoregulatory cytokines produced by blood monocytes, tissue macrophages, and DCs $[76,77]$. Histamine induces the production of IL10 and inhibits that of TNF- $\alpha$ and IL-12 from monocytes. Interestingly, histamine induces TNF- $\alpha$ production from macrophages [78] but not from monocytes or DCs $[79,80]$. Although these observations indicate that histamine exerts important immunoregulatory effects, they also illustrate the heterogeneity of the responses of human immune cells to this mediator [79].

The biologic effects of histamine are mediated by activation of 4 distinct receptors $(\mathrm{H} 1, \mathrm{H} 2, \mathrm{H} 3$, and $\mathrm{H} 4)$ [72]. In the context of $\mathrm{AD}$, we recently showed that human monocytes express the H4R, and that its stimulation leads to a $\mathrm{Ca}^{2+}$ 


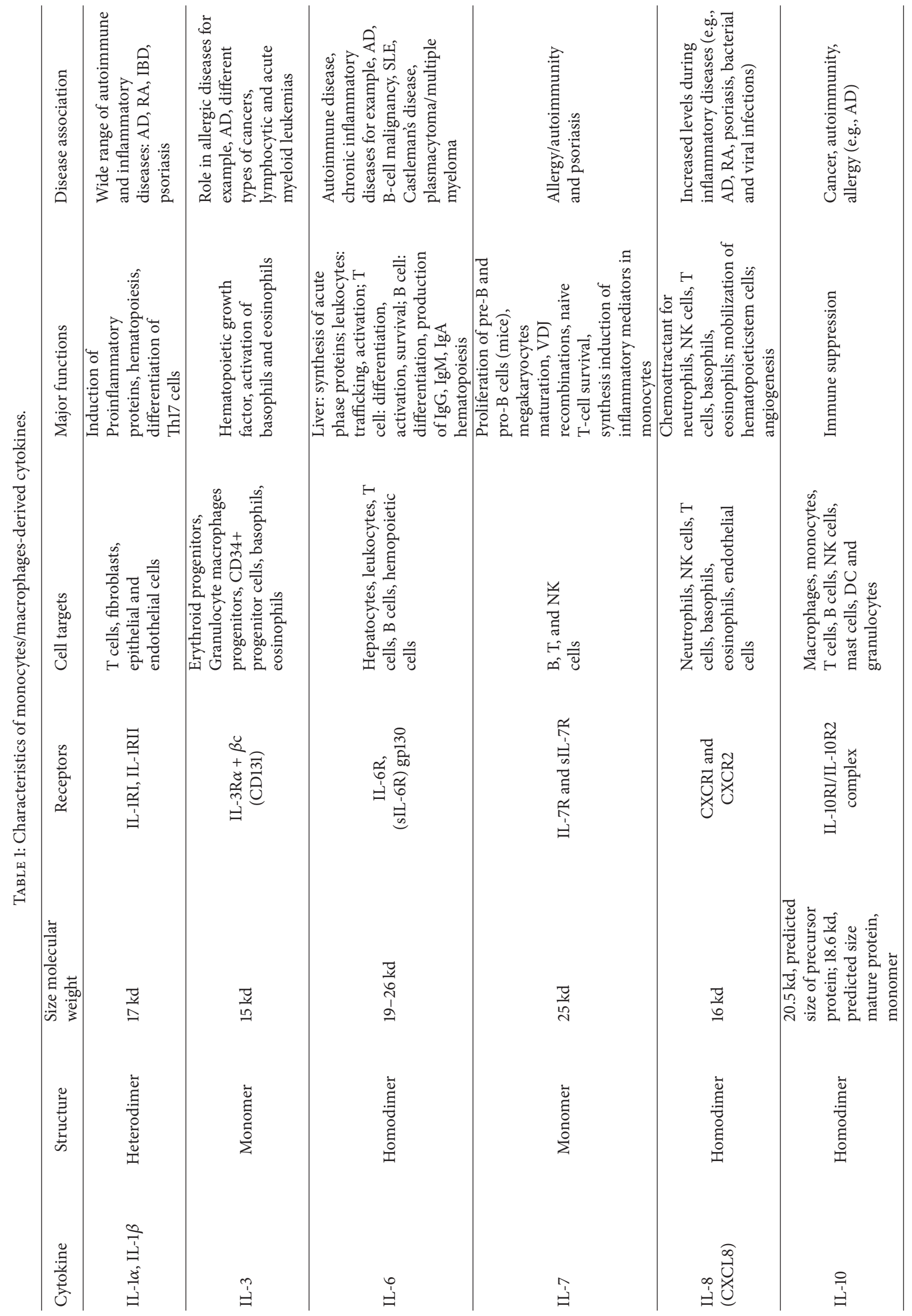




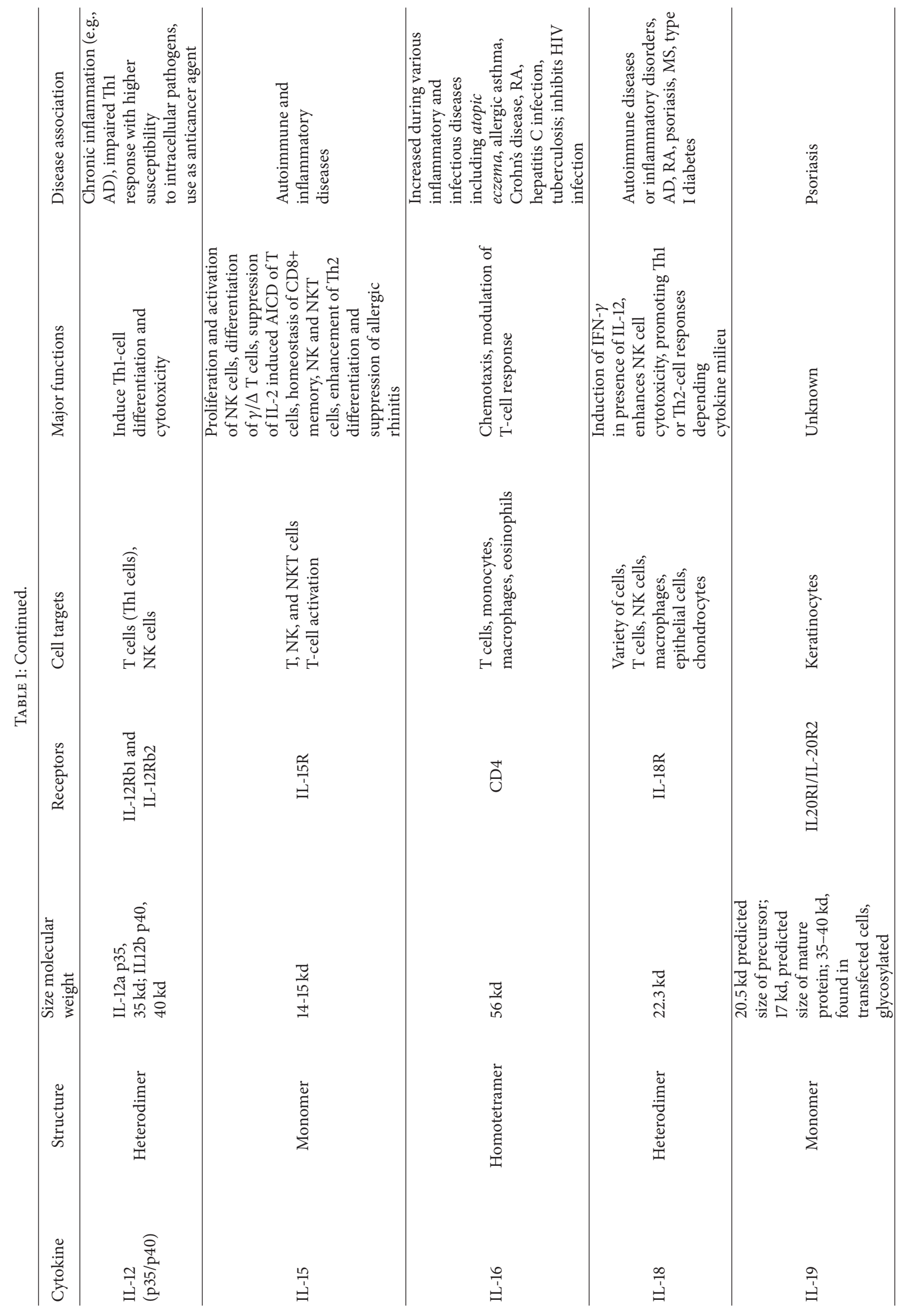




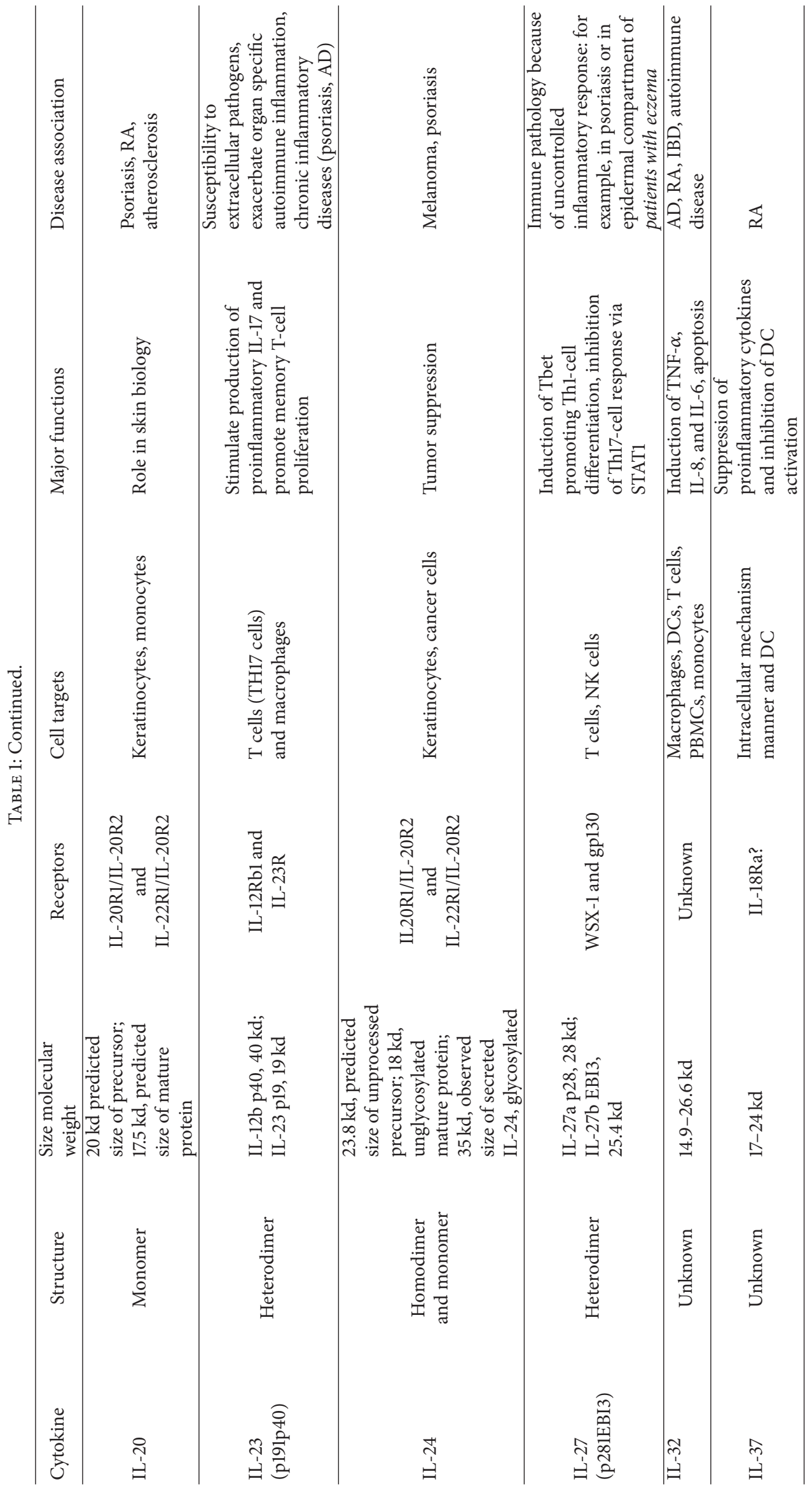




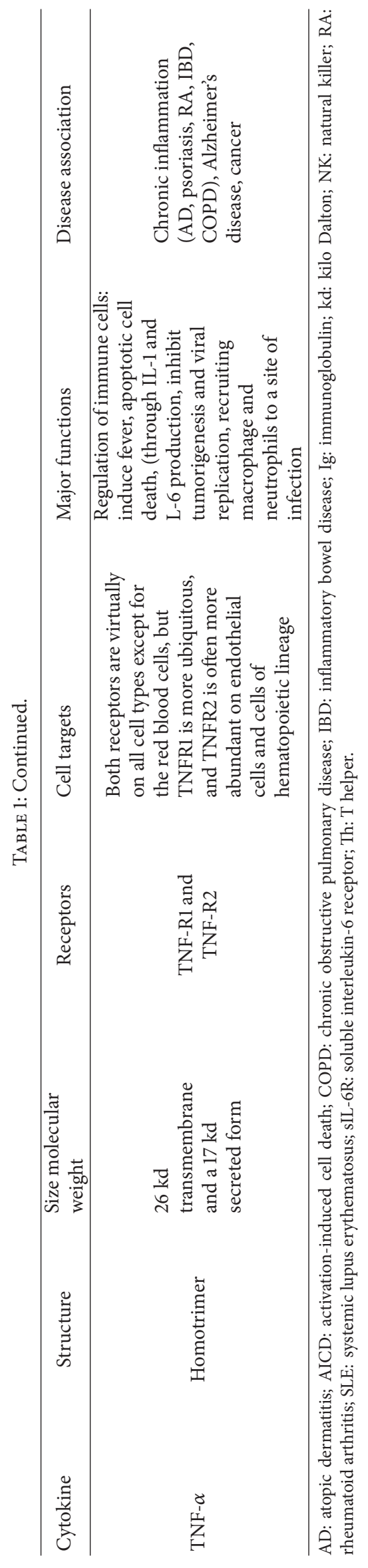


influx and an inhibition of CCL2 production, resulting in a reduction of monocyte recruitment [81].

This could represent a negative feedback mechanism to avoid an overwhelming Th2 environment in case of a persistent histamine release at sites of allergic inflammation and could contribute to the shift from Th2 to Th1 observed in the transition from acute to chronic allergic inflammation such as AD [81].

Furthermore, we showed that histamine downregulates IL-27 production in APCs including monocytes. The downregulation of IL-27 by histamine might be a new mechanism in the pathogenesis of inflammatory skin diseases, in particular, if increased concentrations of histamine are present at sites of inflammation, such as in chronic eczema [82].

5.2. Staphylococcal Exotoxins. Recent findings suggest a role for staphylococcal superantigens in the production of chemokines and cytokines during the development of atopic skin inflammation.

First, superantigen exposure may directly lead to the production of chemokines by $\mathrm{T}$ cells, macrophages, and DCs (CCL1 or CCL18). Second, superantigens may induce the release of effector cytokines such as IL- 4 , IFN- $\gamma$, or IL-31 which in turn may upregulate the expression of chemokines such as CCL1, CCL11, CCL17, CCL18, CCL26, CXCL9, or CXCL10. These chemokines are mainly associated with macrophages. Third, IL-31-induced pruritus may be accompanied by skin injury through scratching resulting in the production of primary proinflammatory cytokines such as IL- $1 \alpha$ and TNF- $\alpha$ which in turn may amplify chemokine production (e.g., CCL20 or CCL27) $[53,73]$.

In addition, we found that staphylococcal exotoxins (SEB or $\alpha$-toxin) significantly upregulates IL-31 receptor A (IL31RA) expression on monocytes and macrophages. Moreover, IL-31 induces proinflammatory cytokines in monocytes and macrophages following staphylococcal exotoxins stimulation. Such data provide a new link between staphylococcal colonization and the worsening of inflammation via IL-31 in monocyte and macrophages [83].

5.3. Cyclic Adenosine Monophosphate (cAMP). Some studies have shown that leukocytes from patients with $\mathrm{AD}$ have increased levels of cAMP-phosphodiesterase activity which results in reduced intracellular cAMP, creating a permissive effect on cell function. This increased activity accounts for subnormal cAMP responses and correlates with increased PGE2 production of monocytes, which inhibits Th1 responses and accentuates IL- 4 secretion by Th2 cells [74, 84].

5.4. Fc Epsilon Receptor I (FceRI) Ligation. FceRI ligation on monocytes of atopic donors induces indoleamine dioxygenase, which is similar to IL-10 in that it is involved in the control of T-cell responses and the induction of tolerance in the immune system [75].

The expression of FceRI and FceRII on monocytes in the peripheral blood is increased in atopic subjects and is significantly higher in patients with extrinsic $\mathrm{AD}$ than in patients with intrinsic AD. Recent concepts support the hypothesis that FceRI-bearing monocytes in the peripheral blood might be the source of subtypes of IgE-bearing DCs in epidermal lesions of patients with $\mathrm{AD}$, which are recruited in the acute phase or during exacerbation of the disease into inflammatory skin by chemokines, cytokines, and other mediators. FceRI on APCs seems to play a pivotal role in modulating the differentiation $[15,75]$.

Taken together, these studies provide new insights in contribution of monocytes and macrophages in the complex network of cytokines and chemokines in $\mathrm{AD}$ as well as role of these cells in the amplification cycle of atopic skin inflammation.

\section{Angiogenesis and Lymphangiogenesis}

Angiogenesis and morphological and functional alterations of microvessels are hallmark features of chronic inflammatory disorders, including AD [85].

Vascular endothelial growth factors (VEGFs) are key regulators of blood vessel growth. The VEGF family includes VEGF-A, -B, -C, -D, and placental growth factor. VEGF-A and $-\mathrm{B}$ are the most important preangiogenic factors, while VEGF-C and -D primarily regulate lymphangiogenesis. High levels of VEGF-A have been detected in skin tissue of AD patients and correlate with disease activity. The vascular changes in the skin of AD patients appear to be linked to the inflammatory process. Besides human mast cells, basophils, eosinophils, and lymphocytes, macrophages as one of the effector cells of skin inflammation, are major sources of a vast array of angiogenic and lymphangiogenic factors such as VEGFs, angiogenin, and IL-8.

Activated macrophages induce neovascularization and contribute to angiogenesis and lymphangiogenesis in inflammatory diseases. Primary human macrophages express angiogenic (VEGF-A and -B) and lymphangiogenic factors (VEGF-C and -D) [86].

Secretory phospholipases A2 enzymes present in the sites of inflammation enhance the expression and release of VEGF-A and -C in human macrophages $[85,86]$.

Using a bacterial pathogen-induced model of acute skin inflammation, it has been demonstrated that the lymphangiogenic growth factors (VEGF-A, -C, and -D) secreted from macrophages in inflamed skin tissue seem to be critical not only in lymphatic vessel expansion, but also in antigen clearance and inflammation resolution through enhancement of lymphangiogenesis [87]. The latter observation is interesting because AD patients have increased colonization and superinfection with Staphylococcus aureus [88]. There is some evidence that angiogenesis is dysregulated in humans and experimental models of AD.

For instance, Shi et al. [89] investigated the possible link of macrophages recruitment and lymphangiogenesis in Keratin14-IL-4 Transgenic (Tg) mouse model of AD. They demonstrated that the density of VEGF-C-expressing CD11b ${ }^{+}$ macrophages increases significantly only within the dermis of lesional skin [89].

Their study suggests that $\mathrm{CD} 1 \mathrm{~b}^{+}$macrophages might contribute to neolymphangiogenesis in $\mathrm{AD}$ by producing VEGF-C [89]. 
The possible role of lymphangiogenesis in different phenotypes and phases of $\mathrm{AD}$ remains elusive. It is likely that better understanding of altered angiogenesis/lymphangiogenesis in different forms and stages of $\mathrm{AD}$ may prove beneficial in the treatment of this common inflammatory skin disorder.

It is possible that specific inhibitors of various mediators (VEGFs) and receptors (VEGFRs, Tie-2, etc.) controlling angiogenesis/lymphangiogenesis may offer novel strategies for dealing with treatment of microvascular changes in inflammatory skin disorders [85]. The possible relevance of angiogenesis/lymphangiogenesis in the pathophysiology and therapy of AD makes the study of vascular remodeling in this disorder a priority for future research.

\section{Conclusions and Perspective}

Much research effort over the last years has concentrated on the identification of dysregulated genetic and immunologic pathways that could lead to the manifestation of AD. Within this dense network of skin immune cells, APCs including macrophages play an outstanding role and are therefore at the center of focus. Macrophages are an essential component of innate immunity and play a central role in inflammation and host defense. Because of their versatile roles in the pathophysiology of $\mathrm{AD}$, their multifaceted character, and their capacities to both promote and prevent the manifestation of allergic skin inflammation, macrophages represent promising cellular targets for therapeutic approaches in the future.

\section{Abbreviations}

$\mathrm{AD}: \quad$ Atopic dermatitis

APC: Antigen presenting cells

AMP: Antimicrobial peptide

cAMP: Cyclic adenosine monophosphate

CCL: Chemokine (C-C motif) ligand

CXCL: Chemokine (C-X-C motif) ligand

CCR: Chemokine (C-C motif) receptor

CD: Cluster of differentiation

DC: Dendritic cells

FceRI: Fc epsilon receptor I

IDEC: Inflammatory dendritic epidermal cell

IFN- $\gamma$ : Interferon-gamma

IL: Interleukin

IP-10: IFN- $\gamma$-induced protein of $10 \mathrm{kd}$

LC: Langerhans cells

LPS: Lipopolysaccharide

LTA: Lipoteichoic acid

MDC: Macrophages derived chemokine

MIG: Monokine induced by gamma interferon

MR: Mannose receptors

NK: Natural killer cells

NLR: Intracellular nucleotide-binding oligomerization domain receptor

NOD: Nucleotide-binding oligomerization domain

PAMP: Pathogen-associated molecular patterns
PBMC: $\quad$ Peripheral blood mononuclear cells

PRR: Pattern-recognition receptor

S. aureus: Staphylococcus aureus

SEB: $\quad$ Staphylococcal enterotoxin B

SNP: $\quad$ Single-nucleotide polymorphism

Th: Thelper cells

TLR: Toll-like receptor

TNF: Tumor necrosis factor

VEGF: Vascular endothelial growth factor.

\section{References}

[1] R. Mirza, L. A. DiPietro, and T. J. Koh, "Selective and specific macrophage ablation is detrimental to wound healing in mice," American Journal of Pathology, vol. 175, no. 6, pp. 2454-2462, 2009.

[2] T. Lucas, A. Waisman, R. Ranjan et al., "Differential roles of macrophages in diverse phases of skin repair," Journal of Immunology, vol. 184, no. 7, pp. 3964-3977, 2010.

[3] B. M. Delavary, W. M. van der Veer, M. van Egmond, F. B. Niessen, and R. H. J. Beelen, "Macrophages in skin injury and repair," Immunobiology, vol. 216, no. 7, pp. 753-762, 2011.

[4] P. J. Murray and T. A. Wynn, "Obstacles and opportunities for understanding macrophage polarization," Journal of Leukocyte Biology, vol. 89, no. 4, pp. 557-563, 2011.

[5] A. F. Valledor, M. Comalada, L. F. Santamaría-Babi, J. Lloberas, and A. Celada, "Macrophage pro-inflammatory activation and deactivation: a question of balance," Advances in Immunology, vol. 108, pp. 1-20, 2010.

[6] M. Boguniewicz and D. Y. M. Leung, "Recent insights into atopic dermatitis and implications for management of infectious complications," Journal of Allergy and Clinical Immunology, vol. 125, no. 1-3, pp. 4-13, 2010.

[7] M. Niebuhr and T. Werfel, "Innate immunity, allergy and atopic dermatitis," Current Opinion in Allergy and Clinical Immunology, vol. 10, no. 5, pp. 463-468, 2010.

[8] C. A. Akdis, M. Akdis, T. Bieber et al., "Diagnosis and treatment of atopic dermatitis in children and adults: European Academy of Allergology and Clinical Immunology/American Academy of Allergy, Asthma and Immunology/PRACTALL Consensus Report," Journal of Allergy and Clinical Immunology, vol. 118, pp. 152-169, 2006.

[9] K. Breuer, A. Kapp, and T. Werfel, "Bacterial infections and atopic dermatitis," Allergy, vol. 56, no. 11, pp. 1034-1041, 2001.

[10] J. J. Leyden, R. R. Marples, and A. M. Kligman, "Staphylococcus aureus in the lesions of atopic dermatitis," British Journal of Dermatology, vol. 90, no. 5, pp. 525-530, 1974.

[11] N. Novak and D. Simon, "Atopic dermatitis-from new pathophysiologic insights to individualized therapy," Allergy, vol. 66, no. 7, pp. 830-839, 2011.

[12] E. Guttman-Yassky, K. E. Nograles, and J. G. Krueger, "Contrasting pathogenesis of atopic dermatitis and psoriasis-part I: clinical and pathologic concepts," Journal of Allergy and Clinical Immunology, vol. 127, no. 5, pp. 1110-1118, 2011.

[13] E. Guttman-Yassky, K. E. Nograles, and J. G. Krueger, "Contrasting pathogenesis of atopic dermatitis and psoriasis-part II: immune cell subsets and therapeutic concepts," Journal of Allergy and Clinical Immunology, vol. 127, no. 6, pp. 1420-1432, 2011. 
[14] C. A. Akdis, M. Akdis, T. Bieber et al., "Diagnosis and treatment of atopic dermatitis in children and adults: European Academy of Allergology and Clinical Immunology/American Academy of Allergy, Asthma and Immunology/PRACTALL Consensus Report," Journal of Allergy and Clinical Immunology, vol. 118, no. 1, pp. 152-169, 2006.

[15] N. Novak, T. Bieber, and D. Y. M. Leung, "Immune mechanisms leading to atopic dermatitis," Journal of Allergy and Clinical Immunology, vol. 112, no. 6, supplement, pp. S128-S139, 2003.

[16] C. Vestergaard, H. Just, J. Baumgartner Nielsen, K. ThestrupPedersen, and M. Deleuran, "Expression of CCR2 on monocytes and macrophages in chronically inflamed skin in atopic dermatitis and psoriasis," Acta Dermato-Venereologica, vol. 84, no. 5, pp. 353-358, 2004.

[17] R. C. M. Kiekens, T. Thepen, A. J. Oosting et al., "Heterogeneity within tissue-specific macrophage and dendritic cell populations during cutaneous inflammation in atopic dermatitis," British Journal of Dermatology, vol. 145, no. 6, pp. 957-965, 2001.

[18] A. Mortellaro, S. C. Wong, J. Fric, and P. Ricciardi-Castagnoli, "The need to identify myeloid dendritic cell progenitors in human blood," Trends in Immunology, vol. 31, no. 1, pp. 18-23, 2010.

[19] A. Lonati, M. A. Mommaas, G. Pasolini, A. Lavazza, G. Rowden, and G. De Panfilis, "Macrophages, but not Langerhans celllike cells of dendritic lineage, express the CD36 molecule in normal human dermis: relevance to downregulatory cutaneous immune responses?" Journal of Investigative Dermatology, vol. 106, no. 1, pp. 96-101, 1996.

[20] V. A. Fadok, M. L. Warner, D. L. Bratton, and P. M. Henson, "CD36 is required for phagocytosis of apoptotic cells by human macrophages that use either a phosphatidylserine receptor or the vitronectin receptor $(\alpha(\mathrm{V}) \beta 3)$," Journal of Immunology, vol. 161, no. 11, pp. 6250-6257, 1998.

[21] M. C. A. A. Tan, A. M. Mommaas, J. W. Drijfhout et al., "Mannose receptor-mediated uptake of antigens strongly enhances HLA class II-restricted antigen presentation by cultured dendritic cells," European Journal of Immunology, vol. 27, no. 9, pp. 2426-2435, 1997.

[22] M. Sugaya, T. Miyagaki, H. Ohmatsu et al., "Association of the numbers of CD163(+) cells in lesional skin and serum levels of soluble CD163 with disease progression of cutaneous T cell lymphoma," Journal of Dermatological Science, vol. 68, pp. 4551, 2012.

[23] W. C. N. Forte, V. C. Guardian, P. A. Mantovani, P. C. L. Dionigi, and M. C. S. Menezes, "Evaluation of phagocytes in atopic dermatitis," Allergologia et Immunopathologia, vol. 37, no. 6, pp. 302-308, 2009.

[24] W. C. N. Forte, J. M. Sumita, A. G. Rodrigues, D. Liuson, and E. Tanaka, "Rebound phenomenon to systemic corticosteroid in atopic dermatitis," Allergologia et Immunopathologia, vol. 33, no. 6, pp. 307-311, 2005.

[25] W. C. N. Forte, M. C. S. Menezes, S. M. C. G. de Oliveira, and S. Bruno, "Atopic dermatitis with mononuclear phagocytic activity deficiency," Allergologia et Immunopathologia, vol. 30, pp. 263-266, 2002.

[26] C. E. McCoy and L. A. J. O’Neill, “The role of toll-like receptors in macrophages," Frontiers in Bioscience, vol. 13, no. 1, pp. 62-70, 2008.

[27] M. Muzio and A. Mantovani, “Toll-like receptors," Microbes and Infection, vol. 2, no. 3, pp. 251-255, 2000.

[28] M. Muzio, D. Bosisio, N. Polentarutti et al., "Differential expression and regulation of toll-like receptors (TLR) in human leukocytes: selective expression of TLR3 in dendritic cells," Journal of Immunology, vol. 164, no. 11, pp. 5998-6004, 2000.

[29] A. Iwasaki and R. Medzhitov, "Toll-like receptor control of the adaptive immune responses," Nature Immunology, vol. 5, no. 10, pp. 987-995, 2004.

[30] A. F. McGettrick and L. A. J. O'Neill, "The expanding family of MyD88-like adaptors in Toll-like receptor signal transduction," Molecular Immunology, vol. 41, no. 6-7, pp. 577-582, 2004.

[31] M. Rehli, "Of mice and men: species variations of Toll-like receptor expression," Trends in Immunology, vol. 23, no. 8, pp. 375-378, 2002.

[32] H. An, H. Xu, Y. Yu et al., "Up-regulation of TLR9 gene expression by LPS in mouse macrophages via activation of NF$\kappa \mathrm{B}$, ERK and p38 MAPK signal pathways," Immunology Letters, vol. 81, no. 3, pp. 165-169, 2002.

[33] B. Beutler, "Inferences, questions and possibilities in Toll-like receptor signalling," Nature, vol. 430, no. 6996, pp. 257-263, 2004.

[34] M. D. Howell, B. E. Kim, P. Gao et al., "Cytokine modulation of atopic dermatitis filaggrin skin expression," Journal of Allergy and Clinical Immunology, vol. 120, no. 1, pp. 150-155, 2007.

[35] A. De Benedetto, R. Agnihothri, L. Y. McGirt, L. G. Bankova, and L. A. Beck, "Atopic dermatitis: a disease caused by innate immune defects?" The Journal of Investigative Dermatology, vol. 129, no. 1, pp. 14-30, 2009.

[36] M. Morr, O. Takeuchi, S. Akira, M. M. Simon, and P. F. Mühlradt, "Differential recognition of structural details of bacterial lipopeptides by Toll-like receptors," European Journal of Immunology, vol. 32, pp. 3337-3347, 2002.

[37] O. Takeuchi, T. Kawai, P. F. Mühlradt et al., "Discrimination of bacterial lipoproteins by Toll-like recepttor 6," International Immunology, vol. 13, no. 7, pp. 933-940, 2001.

[38] S. E. Girardin, L. H. Travassos, M. Hervé et al., "Peptidoglycan molecular requirements allowing detection by Nod1 and Nod2," The Journal of Biological Chemistry, vol. 278, no. 43, pp. 4170241708, 2003.

[39] L. Visser, M. J. Melief, D. van Riel et al., "Phagocytes containing a disease-promoting toll-like receptor/nod ligand are present in the brain during demyelinating disease in primates," American Journal of Pathology, vol. 169, no. 5, pp. 1671-1685, 2006.

[40] J. B. Travers, A. Kozman, N. Mousdicas et al., "Infected atopic dermatitis lesions contain pharmacologic amounts of lipoteichoic acid," Journal of Allergy and Clinical Immunology, vol. 125, no. 1-3, pp. 146-152, 2010.

[41] H. Hasannejad, R. Takahashi, M. Kimishima, K. Hayakawa, and T. Shiohara, "Selective impairment of Toll-like receptor 2mediated proinflammatory cytokine production by monocytes from patients with atopic dermatitis," Journal of Allergy and Clinical Immunology, vol. 120, no. 1, pp. 69-75, 2007.

[42] M. Niebuhr, C. Lutat, S. Sigel, and T. Werfel, "Impaired TLR-2 expression and TLR-2-mediated cytokine secretion in macrophages from patients with atopic dermatitis," Allergy, vol. 64, no. 11, pp. 1580-1587, 2009.

[43] D. Chisholm, L. Libet, T. Hayashi, and A. A. Horner, "Airway peptidoglycan and immunostimulatory DNA exposures have divergent effects on the development of airway allergen hypersensitivities," Journal of Allergy and Clinical Immunology, vol. 113, no. 3, pp. 448-454, 2004.

[44] P. Ahmad-Nejad, S. Mrabet-Dahbi, K. Breuer et al., "The Toll-like receptor 2 R753Q polymorphism defines a subgroup of patients with atopic dermatitis having severe phenotype," 
Journal of Allergy and Clinical Immunology, vol. 113, no. 3, pp. 565-567, 2004.

[45] M. Niebuhr, J. Langnickel, C. Draing, H. Renz, A. Kapp, and T. Werfel, "Dysregulation of toll-like receptor-2 (TLR-2)-induced effects in monocytes from patients with atopic dermatitis: impact of the TLR-2 R753Q polymorphism," Allergy, vol. 63, no. 6, pp. 728-734, 2008.

[46] H. S. Deshmukh, J. B. Hamburger, S. H. Ahn, D. G. McCafferty, S. R. Yang, and V. G. Fowler Jr., "Critical role of NOD2 in regulating the immune response to Staphylococcus aureus," Infection and Immunity, vol. 77, no. 4, pp. 1376-1382, 2009.

[47] L. Franchi, C. McDonald, T. D. Kanneganti, A. Amer, and G. Núñez, "Nucleotide-binding oligomerization domainlike receptors: intracellular pattern recognition molecules for pathogen detection and host defense," Journal of Immunology, vol. 177, no. 6, pp. 3507-3513, 2006.

[48] L. Franchi, T. Eigenbrod, R. Muñoz-Planillo, and G. Nuñez, "The inflammasome: a caspase-1-activation platform that regulates immune responses and disease pathogenesis," Nature Immunology, vol. 10, no. 3, pp. 241-247, 2009.

[49] R. Muñoz-Planillo, L. Franchi, L. S. Miller, and G. Núñez, "A critical role for hemolysins and bacterial lipoproteins in Staphylococcus aureus-induced activation of the Nlrp3 inflammasome," Journal of Immunology, vol. 183, no. 6, pp. 3942-3948, 2009.

[50] S. Kasraie, M. Niebuhr, V. Kopfnagel, O. Dittrich-Breiholz, M. Kracht, and T. Werfel, "Macrophages from patients with atopic dermatitis show a reduced CXCL10 expression in response to staphylococcal a-toxin," Allergy, vol. 67, pp. 41-49, 2012.

[51] M. Akdis, S. Burgler, R. Crameri et al., "Interleukins, from 1 to 37 , and interferon- $\gamma$ : receptors, functions, and roles in diseases," Journal of Allergy and Clinical Immunology, vol. 127, no. 3, pp. 701-721, 2011.

[52] E. S. Fedenko, O. G. Elisyutina, T. M. Filimonova et al., "Cytokine gene expression in the skin and peripheral blood of atopic dermatitis patients and healthy individuals," Self and Nonself, vol. 2, pp. 120-124, 2011.

[53] B. Homey, M. Steinhoff, T. Ruzicka, and D. Y. M. Leung, "Cytokines and chemokines orchestrate atopic skin inflammation," Journal of Allergy and Clinical Immunology, vol. 118, no. 1, pp. 178-189, 2006.

[54] A. Sica and A. Mantovani, "Macrophage plasticity and polarization: in vivo veritas," The Journal of Clinical Investigation, vol. 122, pp. 787-795, 2012.

[55] S. K. Biswas and A. Mantovani, "Macrophage plasticity and interaction with lymphocyte subsets: cancer as a paradigm," Nature Immunology, vol. 11, no. 10, pp. 889-896, 2010.

[56] S. Gordon and F. O. Martinez, "Alternative activation of macrophages: mechanism and functions," Immunity, vol. 32, no. 5, pp. 593-604, 2010.

[57] F. O. Martinez, S. Gordon, M. Locati, and A. Mantovani, "Transcriptional profiling of the human monocyte-to-macrophage differentiation and polarization: new molecules and patterns of gene expression," Journal of Immunology, vol. 177, no. 10, pp. 7303-7311, 2006.

[58] A. Mantovani, A. Sica, S. Sozzani, P. Allavena, A. Vecchi, and M. Locati, "The chemokine system in diverse forms of macrophage activation and polarization," Trends in Immunology, vol. 25, no. 12, pp. 677-686, 2004.

[59] D. M. Mosser, "The many faces of macrophage activation," Journal of Leukocyte Biology, vol. 73, pp. 209-212, 2003.
[60] A. Mantovani, S. Sozzani, M. Locati, P. Allavena, and A. Sica, "Macrophage polarization: tumor-associated macrophages as a paradigm for polarized M2 mononuclear phagocytes," Trends in Immunology, vol. 23, no. 11, pp. 549-555, 2002.

[61] H. Y. Kim, R. H. DeKruyff, and D. T. Umetsu, "The many paths to asthma: phenotype shaped by innate and adaptive immunity," Nature Immunology, vol. 11, pp. 577-584, 2010.

[62] B. N. Melgert, N. H. ten Hacken, B. Rutgers, W. Timens, D. S. Postma, and M. N. Hylkema, "More alternative activation of macrophages in lungs of asthmatic patients," Journal of Allergy and Clinical Immunology, vol. 127, no. 3, pp. 831-833, 2011.

[63] A. P. Moreira and C. M. Hogaboam, "Macrophages in allergic asthma: fine-tuning their pro- and anti-inflammatory actions for disease resolution," Journal of Interferon and Cytokine Research, vol. 31, no. 6, pp. 485-491, 2011.

[64] G. Trujillo, E. C. O’Connor, S. L. Kunkel, and C. M. Hogaboam, "A novel mechanism for CCR4 in the regulation of macrophage activation in bleomycin-induced pulmonary fibrosis," American Journal of Pathology, vol. 172, no. 5, pp. 1209-1221, 2008.

[65] T. A. Reese, H. E. Liang, A. M. Tager et al., "Chitin induces accumulation in tissue of innate immune cells associated with allergy," Nature, vol. 447, no. 7140, pp. 92-96, 2007.

[66] T. A. Wynn, "IL-13 effector functions," Annual Review of Immunology, vol. 21, pp. 425-456, 2003.

[67] J. L. Ather, K. Ckless, R. Martin et al., "Serum amyloid A activates the NLRP3 inflammasome and promotes Th17 allergic asthma in mice," Journal of Immunology, vol. 187, no. 1, pp. 6473, 2011.

[68] A. Nambu and S. Nakae, "IL-1 and allergy," Allergology International, vol. 59, pp. 125-135, 2010.

[69] H. Tsutsui, T. Yoshimoto, N. Hayashi, H. Mizutani, and K. Nakanishi, "Induction of allergic inflammation by interleukin18 in experimental animal models," Immunological Reviews, vol. 202, pp. 115-138, 2004.

[70] D. Y. M. Leung and T. Bieber, "Atopic dermatitis," The Lancet, vol. 361, no. 9352, pp. 151-160, 2003.

[71] M. Grewe, C. A. F. M. Bruijnzeel-Koomen, E. Schöpf et al., "A role for Th1 and Th2 cells in the immunopathogenesis of atopic dermatitis," Immunology Today, vol. 19, no. 8, pp. 359-361, 1998.

[72] M. Triggiani, A. Petraroli, S. Loffredo et al., "Differentiation of monocytes into macrophages induces the upregulation of histamine H1 receptor," Journal of Allergy and Clinical Immunology, vol. 119, no. 2, pp. 472-481, 2007.

[73] B. Homey, S. Meller, T. Savinko, H. Alenius, and A. Lauerma, "Modulation of chemokines by staphylococcal superantigen in atopic dermatitis," Chemical Immunology and Allergy, vol. 93, no. 1, pp. 181-194, 2007.

[74] C. A. Holden, S. C. Chan, and J. M. Hanifin, "Monocyte localization of elevated cAMP phosphodiesterase activity in atopic dermatitis," Journal of Investigative Dermatology, vol. 87, no. 3, pp. 372-376, 1986.

[75] N. Novak, T. Bieber, and N. Katoh, "Engagement of FceRI on human monocytes induces the production of IL-10 and prevents their differentiation in dendritic cells," Journal of Immunology, vol. 167, no. 2, pp. 797-804, 2001.

[76] M. Jutel, T. Watanabe, M. Akdis, K. Blaser, and C. A. Akdis, "Immune regulation by histamine opinion," Current Opinion in Immunology, vol. 14, no. 6, pp. 735-740, 2002.

[77] G. Marone, F. Granata, G. Spadaro, A. Genovese, and M. Triggiani, "The histamine-cytokine network in allergic inflammation," Journal of Allergy and Clinical Immunology, vol. 112, no. 4, supplement, pp. S83-S88, 2003. 
[78] K. Y. Wang, N. Arima, S. Higuchi et al., "Switch of histamine receptor expression from $\mathrm{H} 2$ to $\mathrm{H} 1$ during differentiation of monocytes into macrophages," FEBS Letters, vol. 473, no. 3, pp. 345-348, 2000.

[79] E. Vannier, L. C. Miller, and C. A. Dinarello, "Histamine suppresses gene expression and synthesis of tumor necrosis factor $\alpha$ via histamine $\mathrm{H} 2$ receptors," Journal of Experimental Medicine, vol. 174, no. 1, pp. 281-284, 1991.

[80] G. Caron, Y. Delneste, E. Roelandts et al., "Histamine induces CD86 expression and chemokine production by human immature dendritic cells," Journal of Immunology, vol. 166, no. 10, pp. 6000-6006, 2001.

[81] D. Dijkstra, R. Leurs, P. Chazot et al., "Histamine downregulates monocyte CCL2 production through the histamine H4 receptor," Journal of Allergy and Clinical Immunology, vol. 120, no. 2, pp. 300-307, 2007.

[82] M. Gschwandtner, H. Bunk, B. Köther et al., "Histamine downregulates IL-27 production in antigen-presenting cells," Journal of Leukocyte Biology, vol. 92, pp. 21-29, 2012.

[83] S. Kasraie, M. Niebuhr, and T. Werfel, "Interleukin (IL)31 induces pro-inflammatory cytokines in human monocytes and macrophages following stimulation with staphylococcal exotoxins," Allergy, vol. 65, no. 6, pp. 712-721, 2010.

[84] J. M. Hanifin and S. C. Chan, "Monocyte phosphodiesterase abnormalities and dysregulation of lymphocyte function in atopic dermatitis," Journal of Investigative Dermatology, vol. 105, no. 1, supplement, pp. 84S-88S, 1995.

[85] A. Genovese, A. Detoraki, F. Granata, M. R. Galdiero, G. Spadaro, and G. Marone, "Angiogenesis, lymphangiogenesis and atopic dermatitis," Chemical Immunology and Allergy, vol. 96, pp. 50-60, 2012.

[86] F. Granata, A. Frattini, S. Loffredo et al., "Production of vascular endothelial growth factors from human lung macrophages induced by group IIA and group X secreted phospholipases A2," Journal of Immunology, vol. 184, no. 9, pp. 5232-5241, 2010.

[87] R. P. Kataru, K. Jung, C. Jang et al., "Critical role of CD11b+ macrophages and VEGF in inflammatory lymphangiogenesis, antigen clearance, and inflammation resolution," Blood, vol. 113, no. 22, pp. 5650-5659, 2009.

[88] T. Bieber, "Atopic dermatitis," The New England Journal of Medicine, vol. 358, no. 14, pp. 1483-1494, 2008.

[89] V. Y. Shi, L. Bao, and L. S. Chan, "Inflammation-driven dermal lymphangiogenesis in atopic dermatitis is associated with $\mathrm{CD} 11 \mathrm{~b}+$ macrophage recruitment and VEGF-C up-regulation in the IL-4-transgenic mouse model," Microcirculation, vol. 19, pp. 567-579, 2012. 


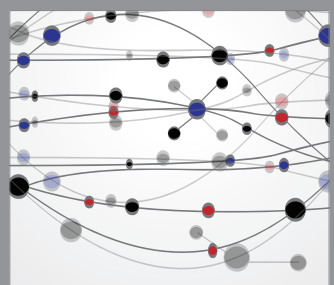

The Scientific World Journal
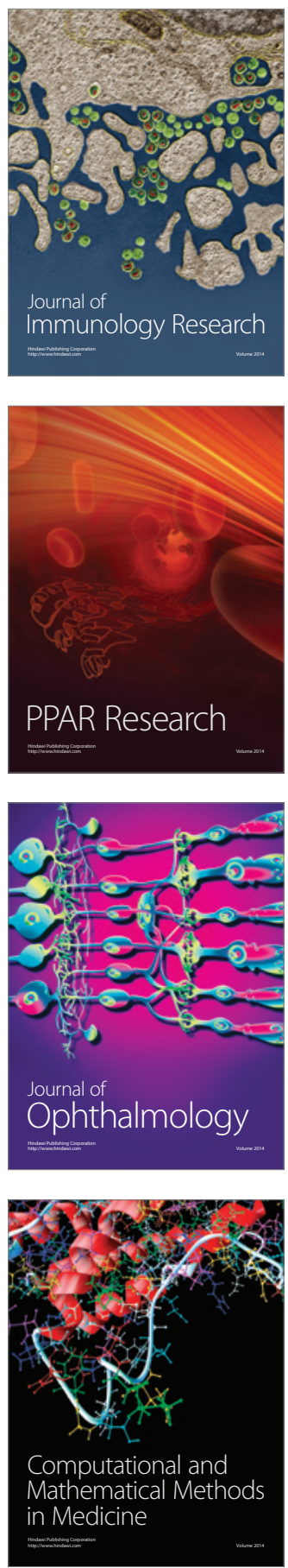

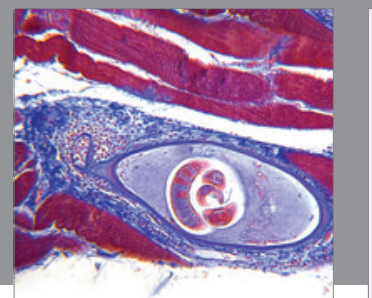

Gastroenterology

Research and Practice
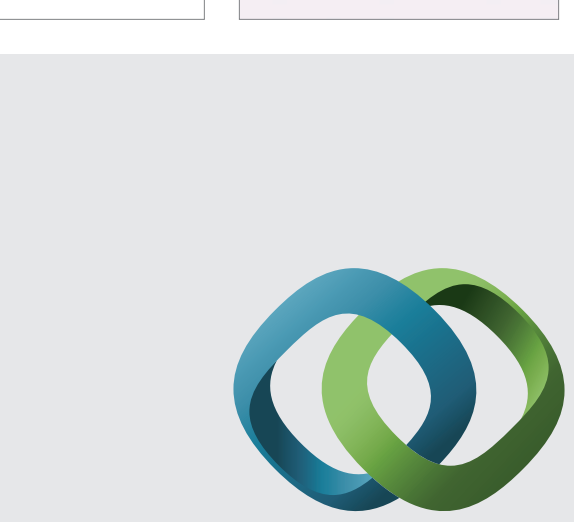

\section{Hindawi}

Submit your manuscripts at

http://www.hindawi.com
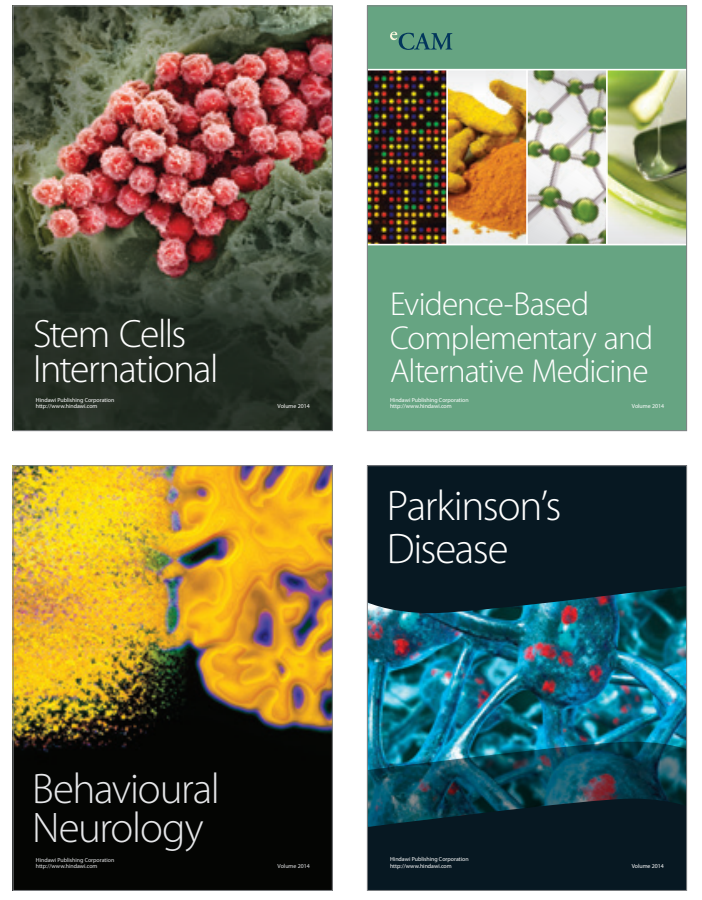
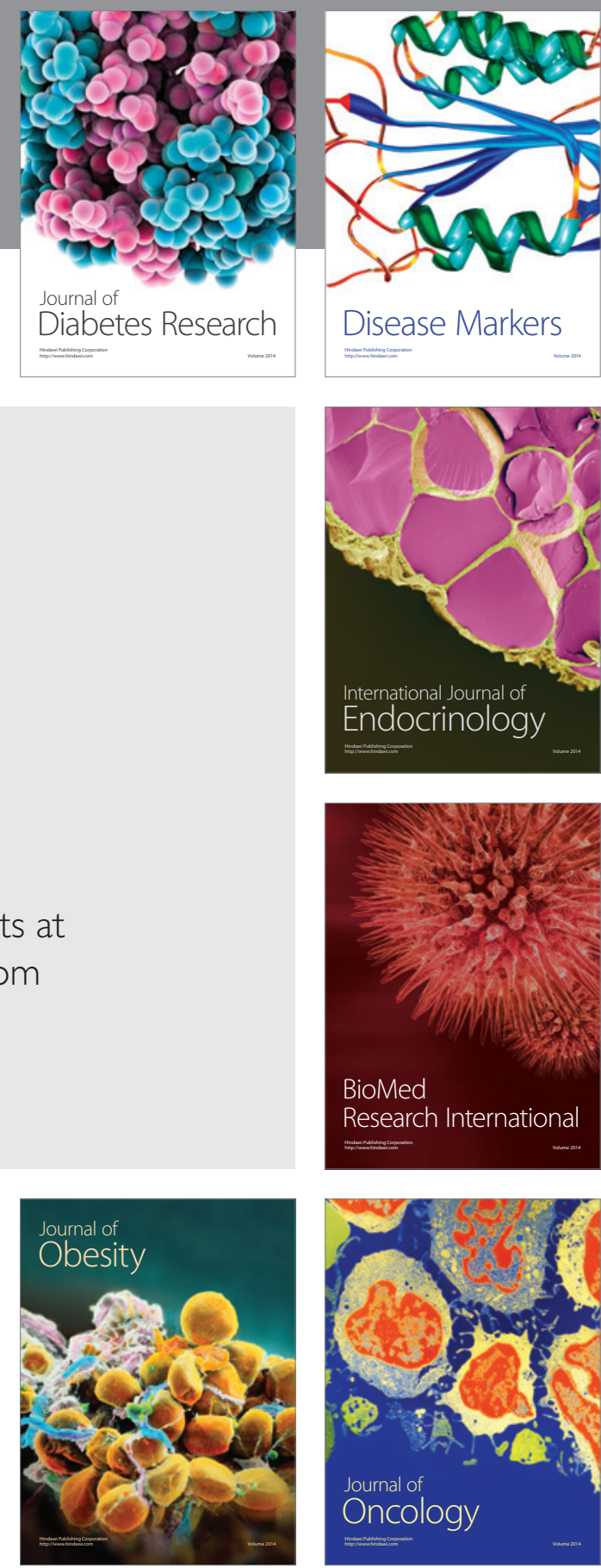

Disease Markers
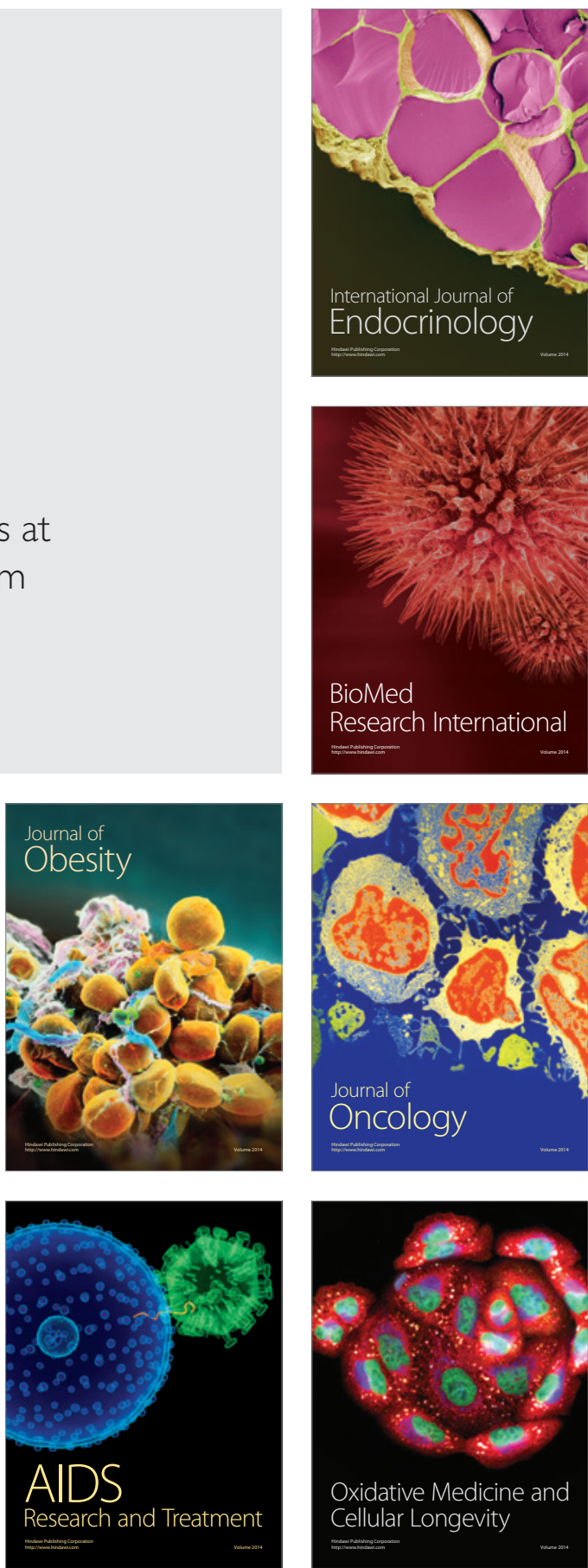